$15^{\text {th }}$ International Conference on

AEROSPACE SCIENCES \& AVIATION TECHNOLOGY,

ASAT - 15 - May 28 - 30, 2013, Email: asat@mtc.edu.eg,

Military Technical College, Kobry Elkobbah, Cairo, Egypt,

Tel: +(202) $24025292-24036138$, Fax: +(202) 22621908

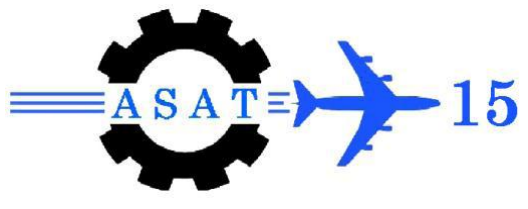

\title{
Effect of Hot Forging and Boron Content on the Mechanical Properties of Dual Phase Steel
}

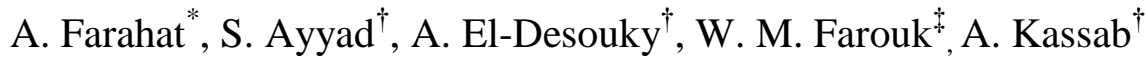

\begin{abstract}
Carbon steel is widely used in different applications such as automotive industry. Boron is used as micro-alloying element to enhance the mechanical properties of carbon steel. The objective of the present work is to study the effect of boron on mechanical properties of dual phase steels. Dual phase (DP) steel is used in the underbody suspension for automotives. The material used in the present study was a carbon alloy steel $(0.29 \mathrm{Cwt} \%)$ with different boron contents 0.0003 and $0.007 \mathrm{wt} \%$. The steels were cast using an open air induction furnace. The molten steel had the shape of Y-blocks. The parts of Y-blocks of alloys $0.0003 \mathrm{~B}$ and $0.007 \mathrm{~B}$ steels were heated up to $1200^{\circ} \mathrm{C}$ and then hot forged producing bars. After hot forging, the bars were subjected to air cooling. In the hardening process, the different alloys $(0.0003 \mathrm{~B}, 0.007 \mathrm{~B})$ were heated up to the intercritical annealing temperatures (between Ac1 and Ac3) for 15 minutes and then water quenched. The resultant microstructures after quenching process were observed as ferrite plus islands of martensite. After that, tempering was done at $300^{\circ} \mathrm{C}, 400^{\circ} \mathrm{C}$ and $500^{\circ} \mathrm{C}$ for different interval times. The experimental results revealed the mechanical properties of the selective alloys were significantly changed by boron content and tempering treatment. By increasing the boron content, hardness gradually increased with small effect on ductility of alloys. By increasing the tempering time and temperature, hardness was gradually decreased while ductility was improved. Compression testing was carried out to determine the compression strength and work-hardening coefficient. The studied steel presented typical manifestations related to dynamic strain aging: serrated flow (the Portevin-Le Chatelier effect).
\end{abstract}

Keywords: Inter-critical annealing, dynamic strain aging, dual phase (DP)

\section{Introduction}

Dual phase (DP) steel is one of the high-strength low-alloy steels, characterized by a microstructure consisting of a dispersion of hard martensite particles in a soft ferrite matrix. Due to its combination of high strength, good ductility and continuous yielding, dual phase steel has been considered to be ideal automobile component materials which require good formability to reduce the weight of vehicle for fuel economy [1]. Dual phase steel has unique properties, such as continuous yielding behaviour (no yield point), low $0.2 \%$ offset yield strength, high tensile strength, high work hardening rate, and unusually high uniform and total elongation [2-4].

Central Metallurgical R\&D Institute, CMRDI, P.O. Box 87 Helwan, Egypt.

$\dagger \quad$ Production Engineering and Mechanical Design Department, Faculty of Engineering, Menoufia University, Shebin El-Kom, Egypt

* Mechanical Engineering Department, Faculty of Engineering, University, Banha, Egypt. 
Dual phase microstructure can be developed in all low-carbon steels by intercritical annealing treatment (ICT) in austenite-ferrite region and cooling it rapidly to room temperature to transform the austenite to martensite [5].It is easy and economical to produce DP steel by using the continuous annealing line equipped with a water quenching device which can produce high strength steels with much lower alloying elements [1]. Tempering has been used successfully to improve the strength/elongation ratio of dual phase steels after intercritical annealing [6-7].

The performance of DP steels mainly depends on their chemical composition such as alloy content of each phase and microstructural parameters such as phase volume fraction and distribution. The reasonable alloy composition design for DP steels can obtain the required mechanical properties at low cost. A few researchers have studied the effect of chemical composition, especially the micro-alloying elements on the mechanical properties of DP steels [8-11].

Boron is used as a micro-alloying element in a number of steels; during cooling from fully austenitized condition, boron increases hardenability $[12,13]$. This effect of boron is related to its ability to segregate to austenite grain boundaries and inhibit the grain boundary nucleation of ferrite. Its action, therefore, is to delay the formation of ferrite relative to the formation of lower temperature transformation products. In the production of dual phase steels, inhibition of ferrite formation would be expected to increase the yield of martensite [14].

The Portevin-Le Chatelier effect (PLC) describes a serrated stress-strain curve, which some materials exhibit as they undergo plastic deformation, specifically inhomogeneous deformation. This effect has been long associated with dynamic strain aging or the competition between diffusing solutes pinning dislocations and dislocation breaking free of this stoppage [15]. Because the PLC effect is related to a strengthening mechanism, the strength of steel may increase; however, the plasticity and ductility of a material afflicted by the PLC effect decrease drastically.

The aim of this work is the processing of dual phase steel from hot forged carbon steel containing boron $(0.0003 \mathrm{~B}$ and $0.007 \mathrm{~B})$ and $(0.29 \% \mathrm{C})$ then subjected to a heat-treatment cycle for use in the under body suspension of automotives where a good combination of strength and formability is necessary.

\section{Experimental Procedure}

\subsection{Materials}

Medium carbon steel was prepared by using an open air induction furnace. The $0.29 \% \mathrm{C}$ steel with Fe-B (20\%B) was melted together to produce steel in the form of Y-blocks with chemical composition as listed in Table 1. The Y-blocks were machined and prepared for hot forging by removing the sand layer. The materials were heated up to $1200^{\circ} \mathrm{C}$ and hold for 30 minute and then were subjected to hot forging and the cross-sectional area was reduced down to $20 \mathrm{~mm}$ with $90 \%$ cross-section reduction. Manufacturing of test specimens with $13.75 \mathrm{~mm}$ diameter and $20 \mathrm{~mm}$ height was carried out after hot forging.

\subsection{Thermomechanical Processing}

DP microstructure was achieved by annealing at different intercritical temperatures $\left(770^{\circ} \mathrm{C}\right.$, $790^{\circ} \mathrm{C}$ and $810^{\circ} \mathrm{C}$ ) depending on the dilatation curves for $15 \mathrm{~min}$ and cooling in water. After Quenching the samples were tempered at different temperatures $\left(300^{\circ} \mathrm{C}, 400^{\circ} \mathrm{C}\right.$ and $\left.500^{\circ} \mathrm{C}\right)$ for $(0,30,45,60$ and 120 minutes) and subsequently cooled in air as shown in Fig.1. 
Table 1 Chemical composition, wt\%

\begin{tabular}{rrrrrrrrr}
\hline \hline Alloy & $\mathrm{C}$ & $\mathrm{Si}$ & $\mathrm{Mn}$ & $\mathrm{P}$ & $\mathrm{S}$ & $\mathrm{Cr}$ & $\mathrm{Fe}$ & $\mathrm{B}$ \\
\hline 3B & 0.2652 & 0.3625 & 1.197 & 0.0199 & 0.0067 & 0.1667 & 97.9977 & 0.0003 \\
\hline 70B & 0.2900 & 0.2996 & 1.314 & 0.0302 & 0.0195 & 0.0699 & 97.975 & 0.007 \\
\hline \hline
\end{tabular}

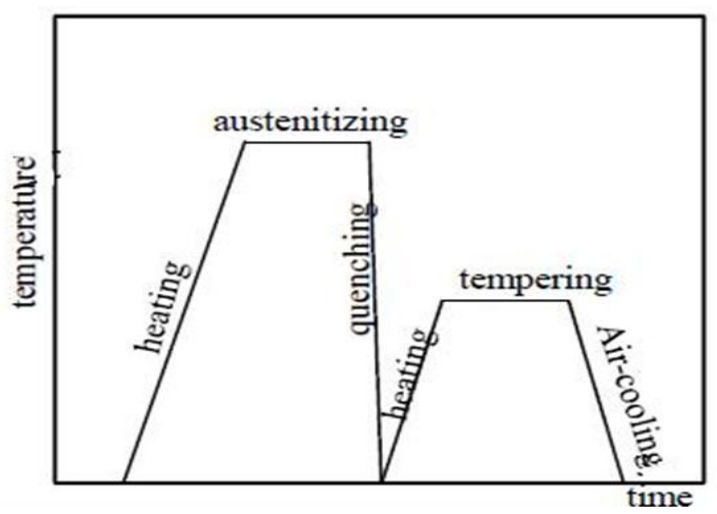

Fig.1 Thermomechanical treatment

\subsection{Microstructure Investigations}

Optical microscope and scanning electron microscope were used to investigate the microstructure for as-cast, as-forged and heat-treated materials after etching the specimens with $0.2 \%$ nital. The volume fraction of martensite for same specimens was determined by an image analyzer on metallographic sections.

\subsection{Mechanical Testing}

Microhardness measurements were conducted on polished surface of the same specimens using load $0.5 \mathrm{~kg}$. Compression tests were carried out at room temperature for hot forged and heat-treated materials (same specimens) according to ASTM E9.

\section{Results and Discussion}

\subsection{Microstructure and Martensite Volume Fraction}

The microstructures of the as-cast and hot forged samples for both steel (3B and 70B) are shown in Fig.2. It is clear that the microstructure after casting consists mainly of ferrite matrix (white phase) and pearlite (dark phase). Fig.3 shows the SEM micrograph of these steels. It is apparent that hot forging highly grain refined the matrix.

By intercritical annealing of $3 \mathrm{~B}$ and $70 \mathrm{~B}$ steels at $770^{\circ} \mathrm{C}, 790^{\circ} \mathrm{C}$ and $810^{\circ} \mathrm{C}$ and subsequent water quenching, the ferritic-martensitic microstructure was obtained. Fig.4. shows the optical micrograph of this microstructure. The volume fractions of martensite after annealing for both steels are listed in Table.2. It is obvious that the martensite volume fraction increases as the amount of boron and inter-critical annealing temperatures are increased as shown in Fig.5.

The quenched specimens were then tempered at different temperatures. The microstructures of specimens tempered at $500^{\circ} \mathrm{C}$ for 120 minute have been shown in Fig.6. The microstructure of tempered specimens clearly differs from the non-tempered samples. It is clear that the ferrite volume fraction and cementite increase due to dissociation of martensite to cementite and ferrite totally. 

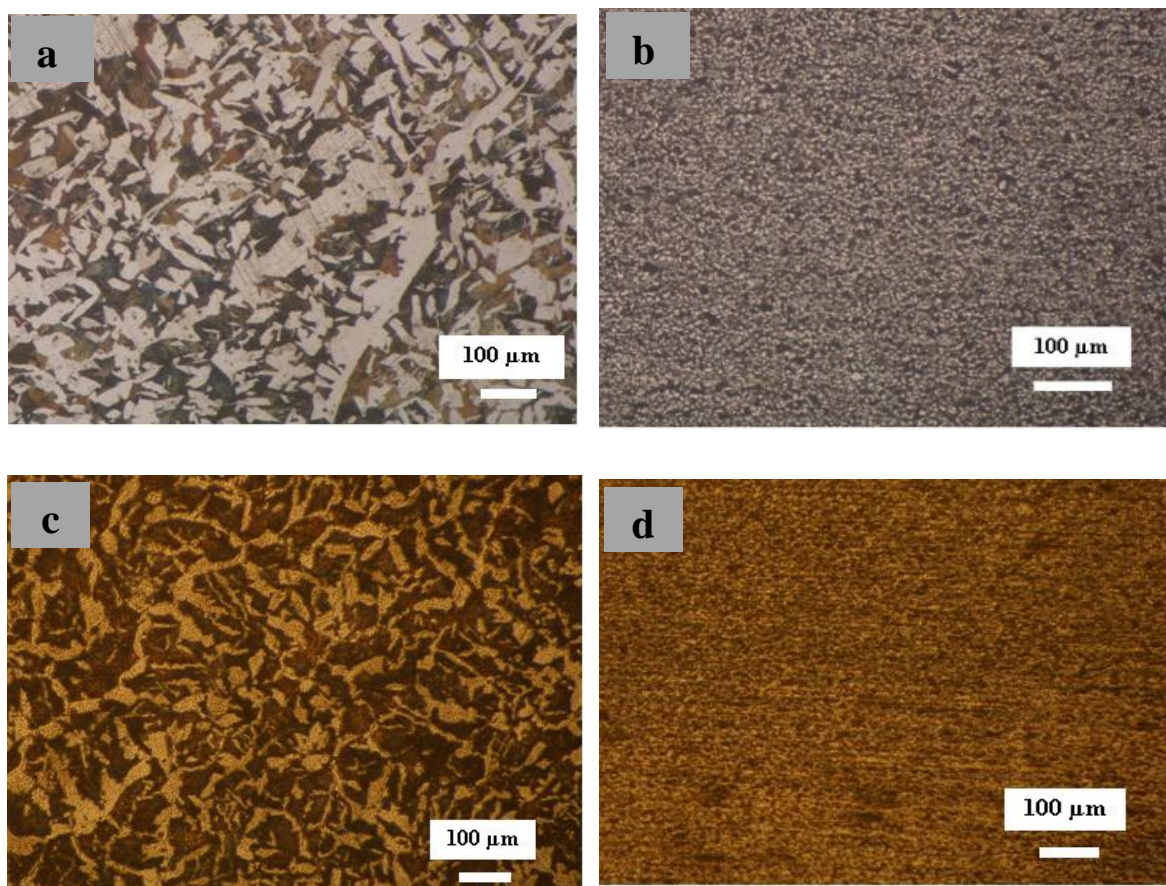

Fig.2. (a) As-cast microstructure of 3B steel (b) Optical micrograph of hot forged of 3B (c) As-cast microstructure of 70B steel (d) Optical micrograph of hot forged of 70B
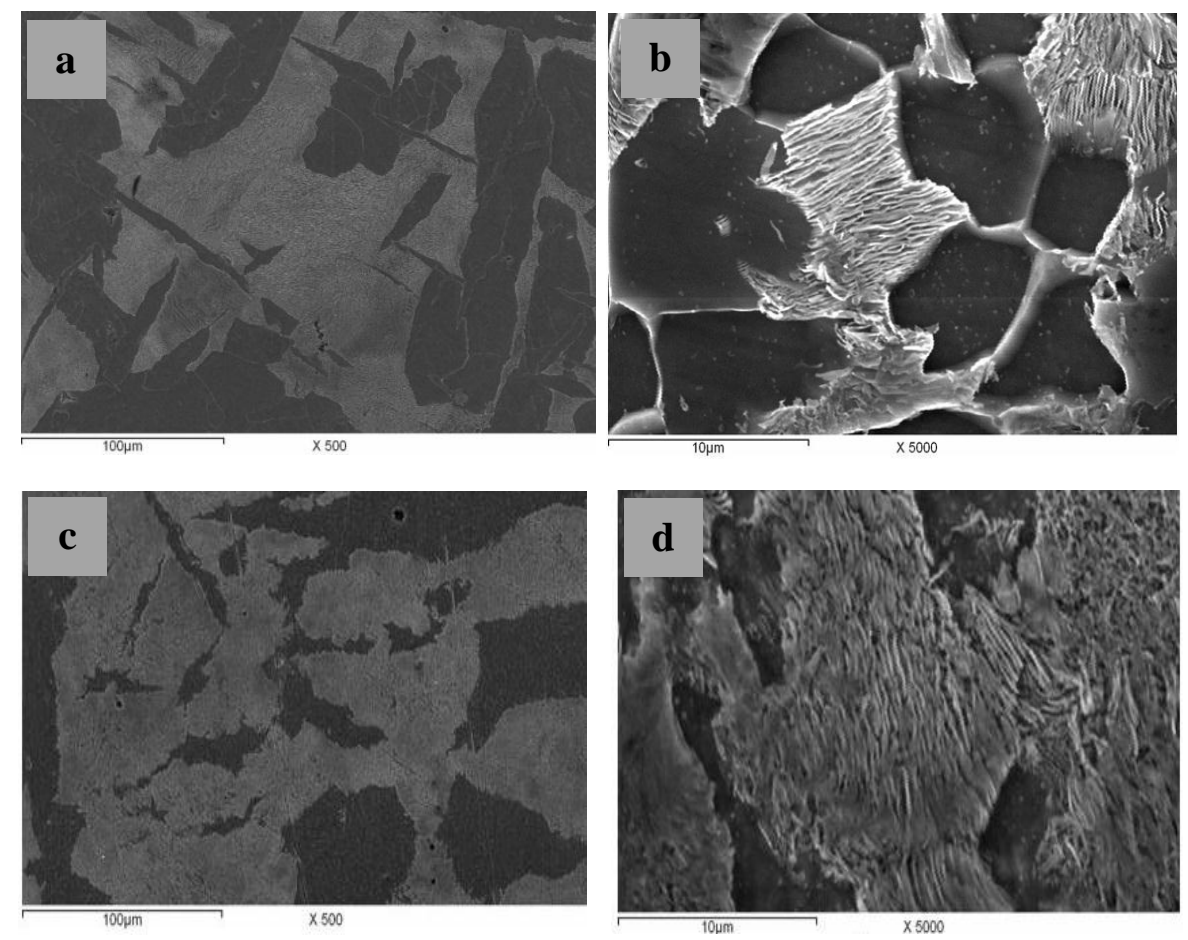

Fig.3. SEM micrograph of: (a) 3B as-cast steel (b) 3B hot forged steel (c) $70 \mathrm{~B}$ as-cast steel (d) $70 \mathrm{~B}$ hot forged steel 

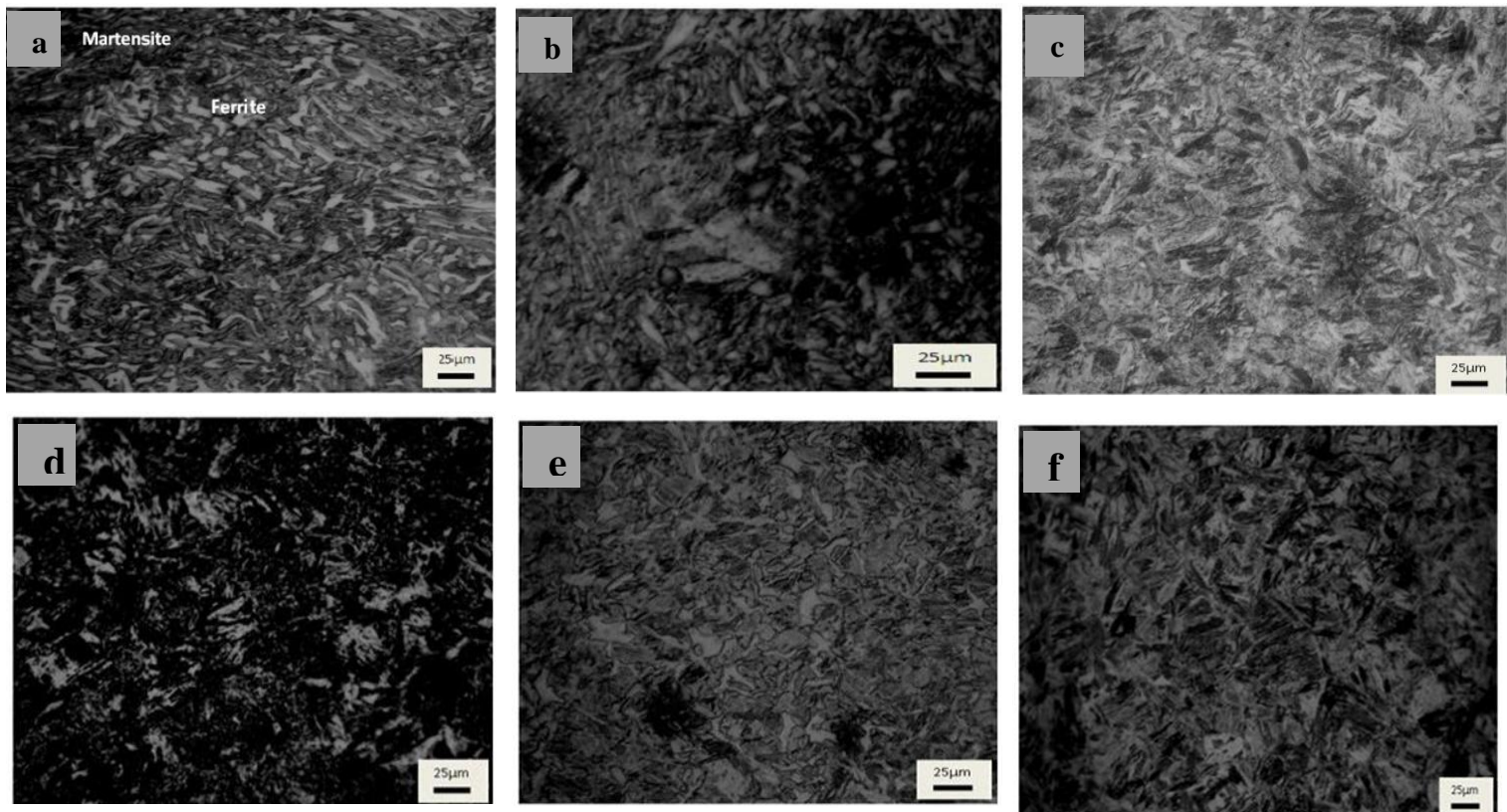

(a) $770^{\circ} \mathrm{C}$, 3B steel; (b) $790^{\circ} \mathrm{C}, 3 \mathrm{~B}$ steel; (c) $810^{\circ} \mathrm{C}$, 3B steel; (d) $770^{\circ} \mathrm{C}, 70 \mathrm{~B}$ steel; (e) $790^{\circ} \mathrm{C}, 70 \mathrm{~B}$ steel;

(f) $810^{\circ} \mathrm{C}, 70 \mathrm{~B}$.

Fig.4. Optical microstructure of samples inter-critical annealed for $15 \mathrm{~min}$

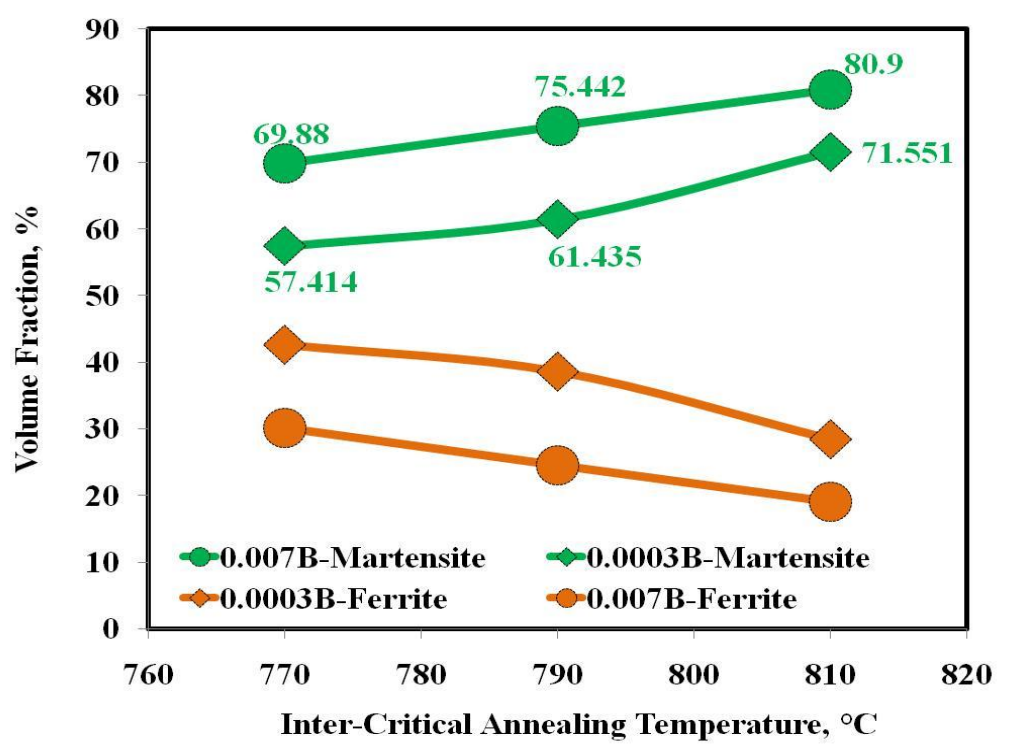

Fig.5. Effect of inter-critical annealing temperature on the martensite and ferrite volume fractions for both steels

\subsection{Hardness Results}

\subsubsection{Hardness of 3B steel}

The mean hardness value of the as-cast $3 \mathrm{~B}$ steel is $147 \mathrm{HV}$ and reaches $172.5 \mathrm{HV}$ after hot forging, air cooled. Hardness slightly increase due to homogenization of fine precipitate $\mathrm{Fe}_{23}(\mathrm{C}, \mathrm{B})_{6}[16]$ and grain refinement. Figure 7shows the hardness (HV) distribution of 3B steel inter-critically annealed at $770^{\circ} \mathrm{C}$ for 15 minuts followed by water quenching. It is obvious that the average hardness value is $360.6 \mathrm{HV}$ as stated in Table.3. It is found that the hardness value after inter-critical annealing at $770^{\circ} \mathrm{C}$ then water quenching reaches $361 \mathrm{HV}$. 
This hardness value is higher than the as-cast (147HV) and hot forged $(172.5 \mathrm{HV})$ ones and is attributed to the existence of martensite.

By applying the tempering process, it is found that hardness decreases as tempering time and temperature are increased due to dissociation of martensite phase into ferrite and cementite as shown in Fig.8.

Table.2. Effect of inter-critical annealed temperature and then water quenched on the martensite volume fraction for both steels

\begin{tabular}{ccc}
\hline \hline $\begin{array}{c}\text { Inter-critical annealing } \\
\text { Temperature, }{ }^{\circ} \mathbf{C}\end{array}$ & $\begin{array}{c}\text { Martensite Volume } \\
\text { Fraction, \%, 3B steel }\end{array}$ & $\begin{array}{c}\text { Martensite Volume } \\
\text { Fraction, \%, 70B steel }\end{array}$ \\
\hline 770 & 57.414 & 69.88 \\
\hline 790 & 61.435 & 75.44 \\
\hline 810 & 71.551 & 80.9 \\
\hline \hline
\end{tabular}
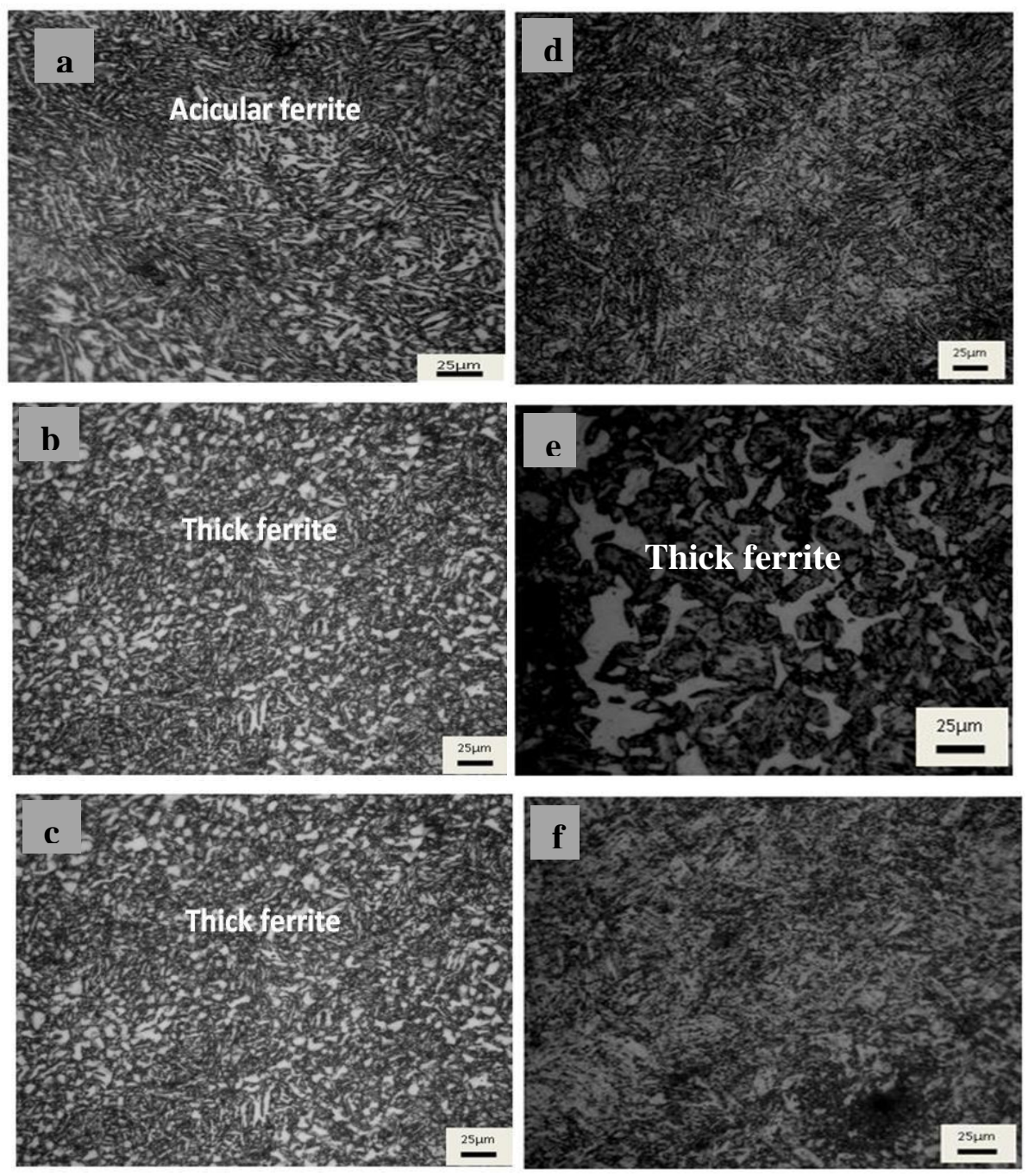

(a) $770^{\circ} \mathrm{C}, 3 \mathrm{~B}$ steel; (b) $790^{\circ} \mathrm{C}, 3 \mathrm{~B}$ steel; (c) $810^{\circ} \mathrm{C}, 3 \mathrm{~B}$ steel; (d) $770^{\circ} \mathrm{C}, 70 \mathrm{~B}$ steel; (e) $790^{\circ} \mathrm{C}, 70 \mathrm{~B}$ steel; (f) $810^{\circ} \mathrm{C}, 70 \mathrm{~B}$.

Fig.6. Optical microstructure of samples tempered at $500^{\circ} \mathrm{C}$ for 120 minutes 


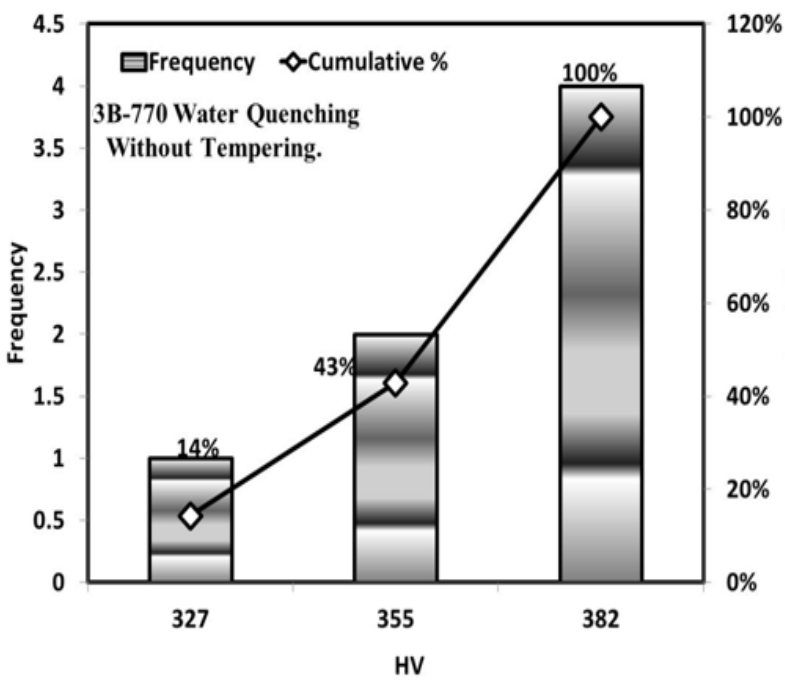

Fig.7. Hardness distribution of $3 B$ steel

$\mathbf{7 7 0}^{\circ} \mathrm{C}$
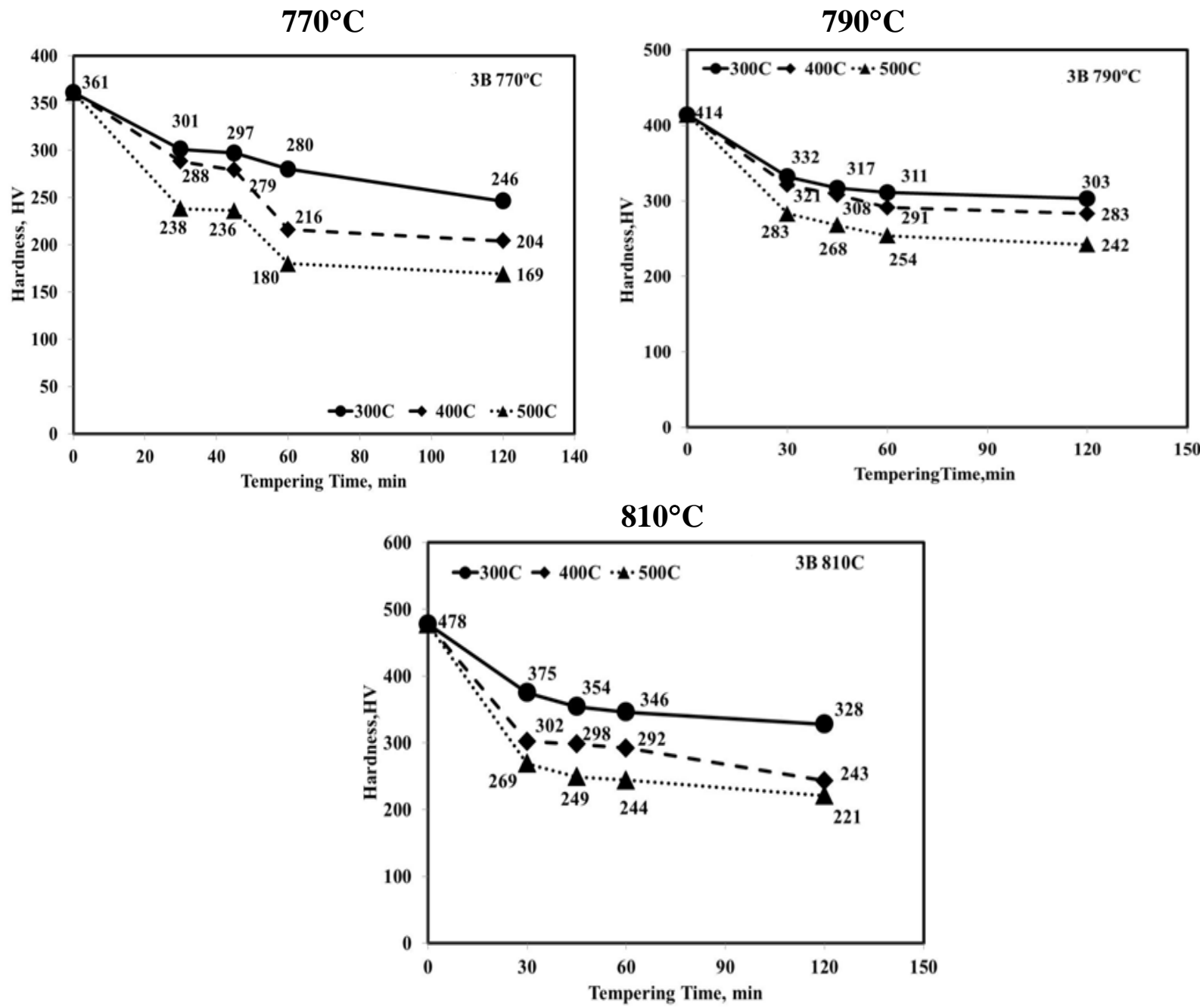

Fig.8. Effect of tempering temperature and time on hardness value of 3B steel

\subsubsection{Hardness of 70B steel}

The mean hardness value of the as-cast 70B steel is $172.2 \mathrm{HV}$ and reaches $190.9 \mathrm{HV}$ after hot forging, air cooled. Hardness slightly increases due to homogenization of fine precipitate $\mathrm{Fe}_{23}(\mathrm{C}, \mathrm{B})_{6}$ and grain refinement. Fig.9 shows the hardness (HV) distribution of 70B steel 
inter-critically annealed at $770^{\circ} \mathrm{C}$ for 15 minutes followed by water quenching. It is obvious that the average hardness value is $478 \mathrm{HV}$ as stated in Table. 4 .

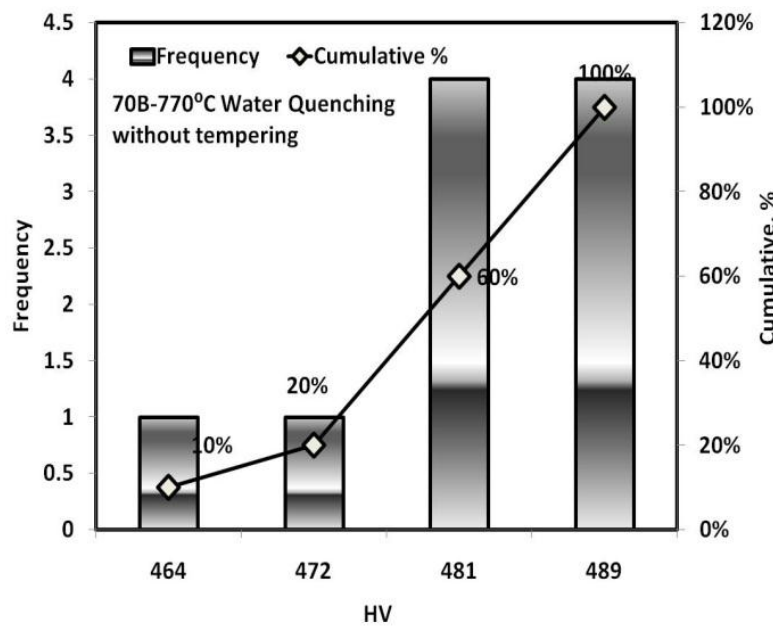

Table.4. Hardness statistical analysis of 70B intercritically annealed steel

\begin{tabular}{c|c}
\hline \hline \multicolumn{2}{c}{ Hv0.5Kg-70B steel } \\
\hline Mean & 478.2 \\
\hline Standard Error & 2.3 \\
\hline Median & 478.0 \\
\hline Mode & 477.0 \\
\hline Standard Deviation & 7.4 \\
\hline Sample Variance & 54.8 \\
\hline \hline
\end{tabular}

Fig.9. Hardness distribution of 70B steel

It is found that the hardness value reaches $478 \mathrm{HV}$. This hardness value is higher than the ascast and hot forged ones and is attributed to the existence of martensite. By applying the tempering process, it is found that hardness decreases as tempering time and temperature are increased as shown in Fig.10.
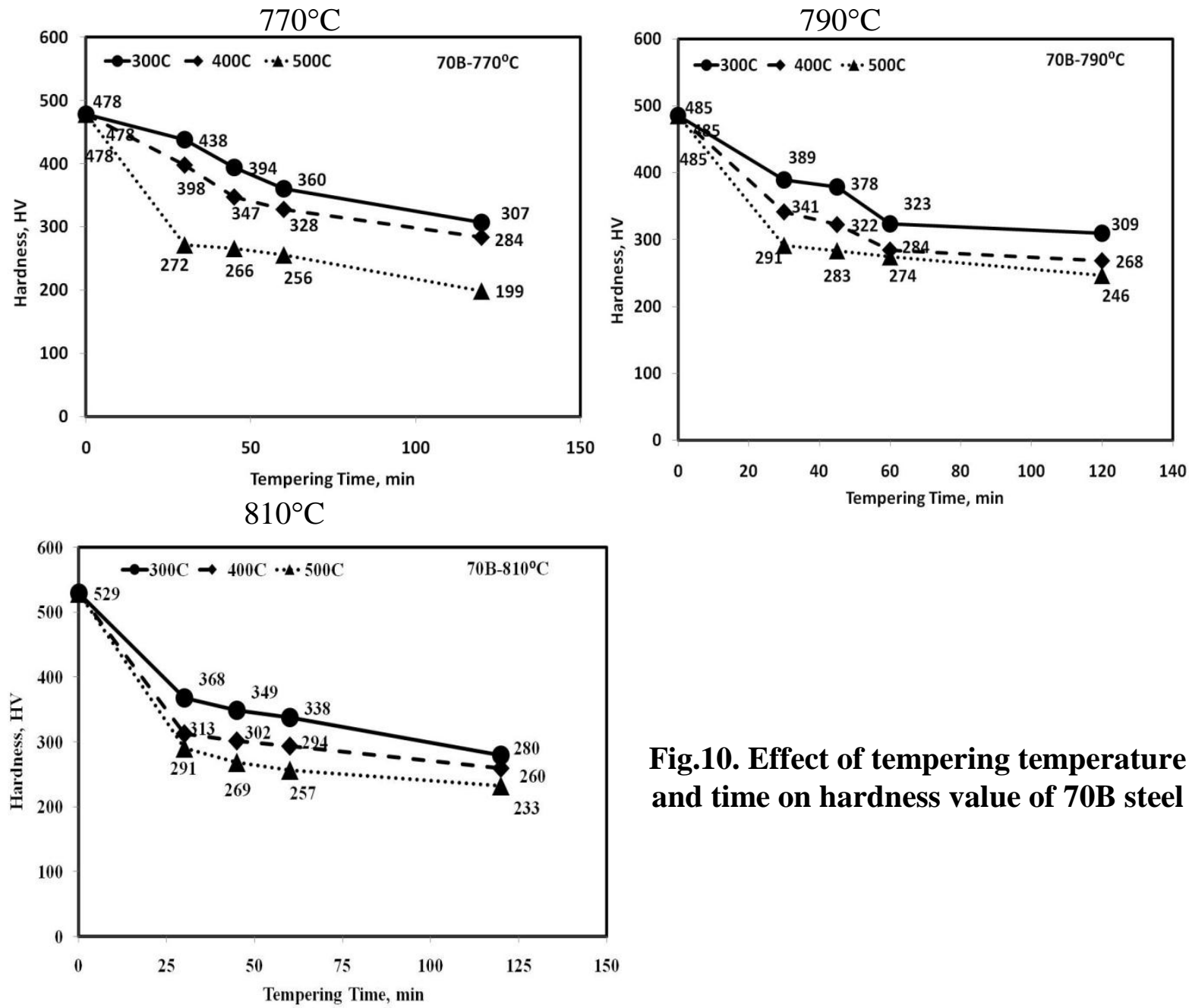

Fig.10. Effect of tempering temperature and time on hardness value of $70 \mathrm{~B}$ steel 


\subsubsection{The effect of inter-critical annealing temperature on the hardness value for both steels}

Figure 11 demonstrates the effect of boron content and different inter-critical annealing temperatures on the hardness. The hardness value increases with increasing boron content and inter-critical annealing temperature (from 10\% to 32\%). This is attributed to formation of $\mathrm{Fe}_{23}(\mathrm{~B}, \mathrm{C})_{6}$ precipitate and increasing the volume fraction of martensite. The combined effect of both boron content and inter-critical annealing temperature on hardness is $46.5 \%$.

\subsection{Compression Properties}

\subsubsection{General behavior of compression flow curves}

Figure 12 shows the general behaviour of compression flow curves of $3 \mathrm{~B}$ steels tested at room temperature and initial strain rate $\left(4 \times 10^{-4}\right)$ of inter-critically annealed steel followed by water quenching and then tempering. The compression curve after inter-critical annealing exhibit single stage plastic flow curve while after tempering it provides two stage ones. The first stage demonstrates the plastic behavior of the compression specimens without cracking. The second stage of the stress-strain compression curve gives plastic line of higher slope due to side cracks. Therefore, in our study the second stage of the plastic flow of the stress-strain compression curve is omitted and the true compression stress-strain curve is used to judge material plastic behavior. It is apparent that the compression curves give serration due to dynamic strain aging. All the tested materials show the same behaviour.

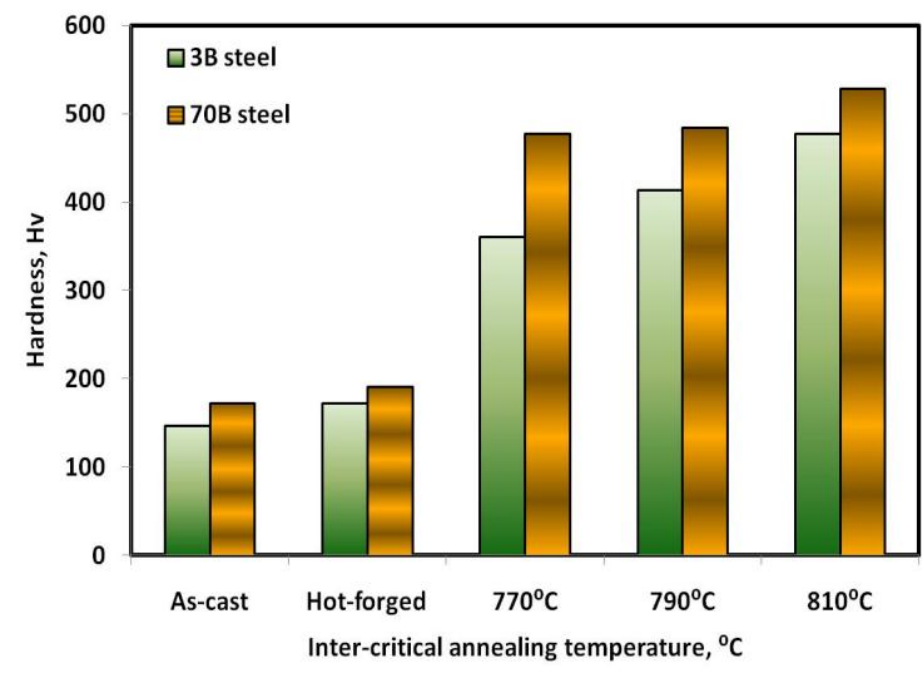

Fig.11. Effect of boron content and different inter-critical annealing temperature on the hardness for both steels

\subsubsection{Compression properties for both steels}

Figures 13 and 16 show the effect of tempering temperature and time on the true compressive strength at different intercritical annealing temperatures $\left(770^{\circ} \mathrm{C}, 790^{\circ} \mathrm{C}\right.$ and $\left.810^{\circ} \mathrm{C}\right)$ which decrease with increasing the tempering temperature and time due to dissociation of martensite into cementite and ferrite. It is also apparent that they have maxima at different time due to dynamic strain aging.

Figures 14 and 17 show the effect of tempering temperature and time on the work hardening exponent at different intercritical annealing temperatures $\left(770^{\circ} \mathrm{C}, 790^{\circ} \mathrm{C}\right.$ and $\left.810^{\circ} \mathrm{C}\right)$ which increase with increasing the tempering temperature. It is also apparent that they have maxima at different time due to dynamic strain aging. 

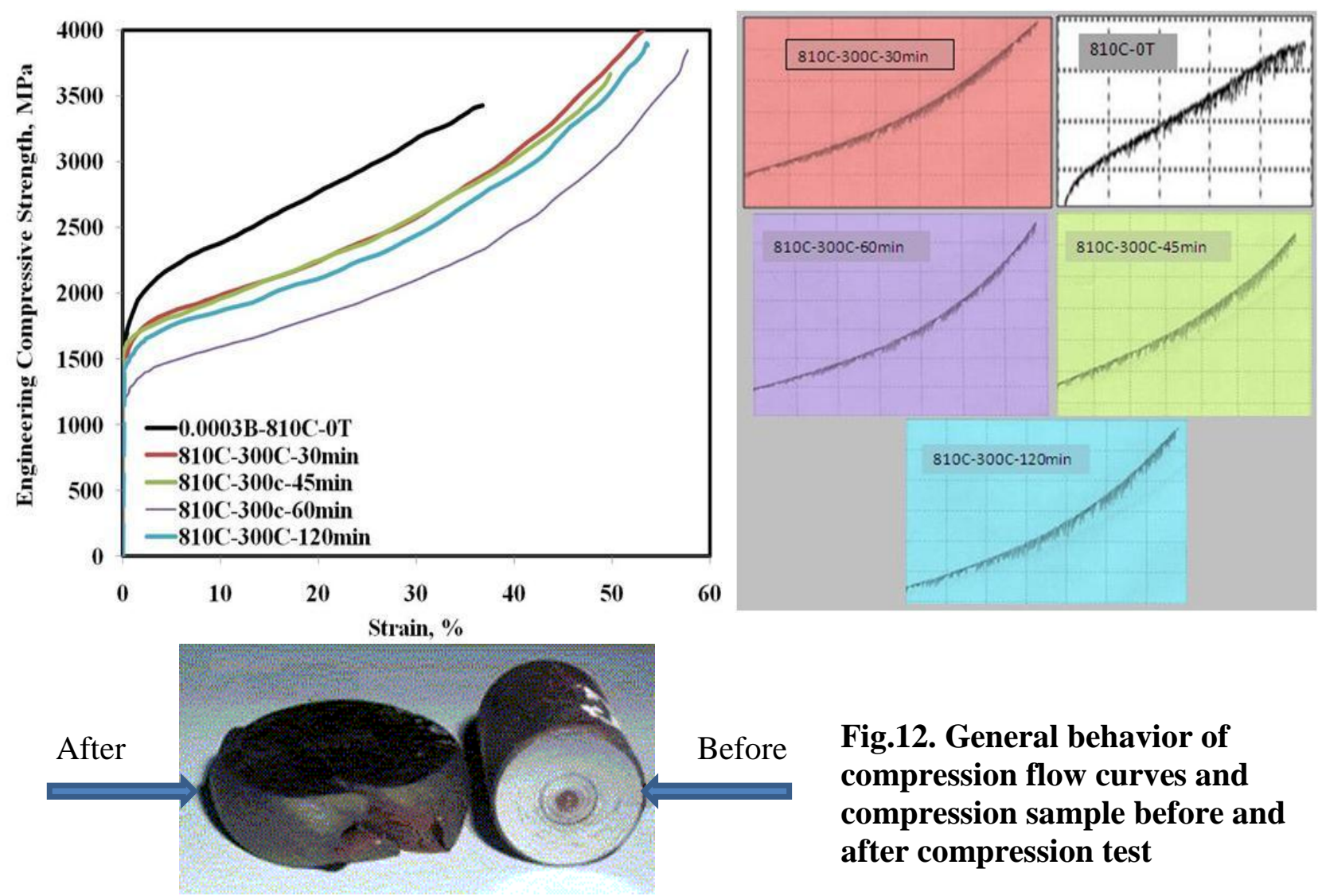

Before Fig.12. General behavior of compression flow curves and compression sample before and after compression test
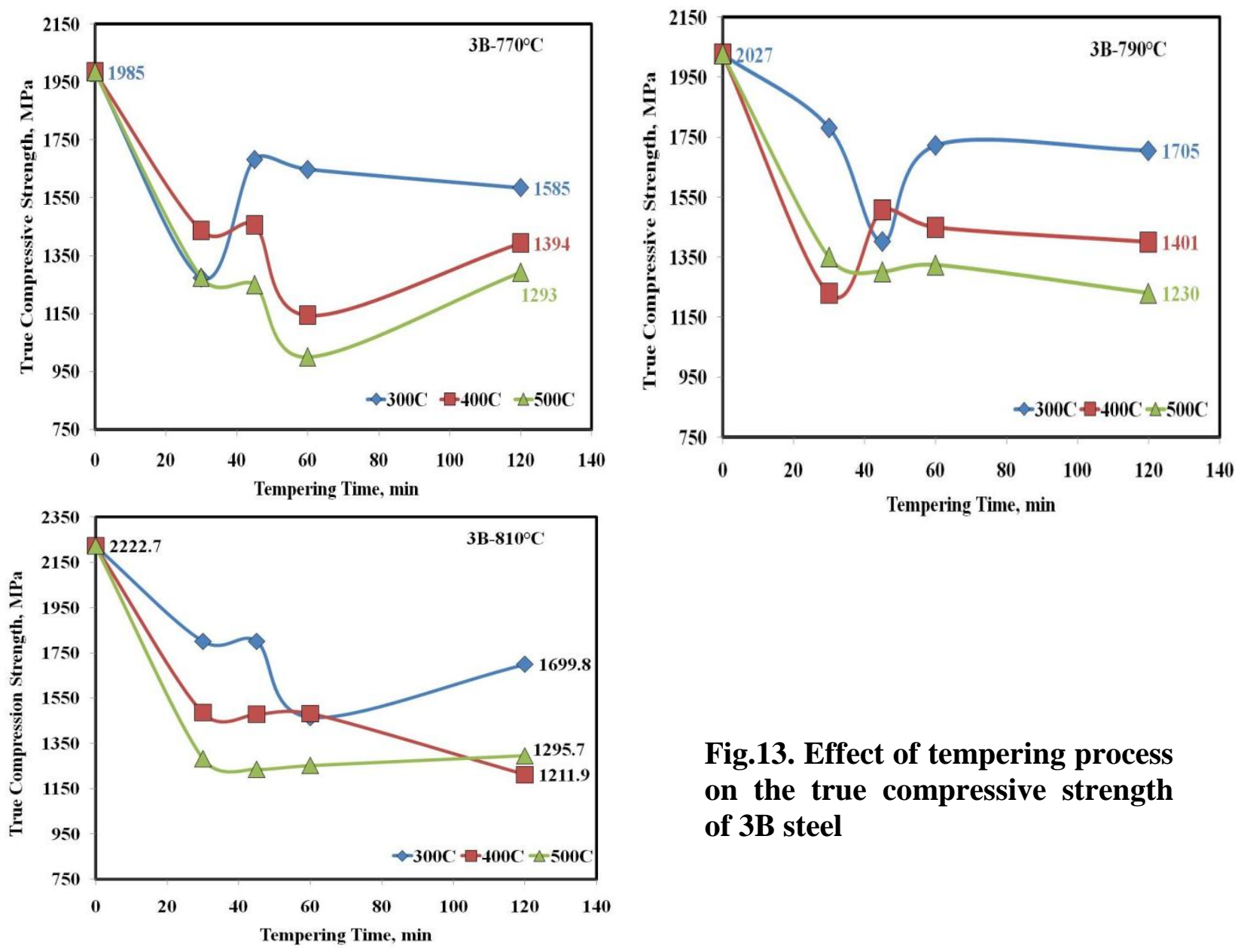

Fig.13. Effect of tempering process on the true compressive strength of 3B steel 
Figures 15 and 18 show the effect of tempering temperature and time on the uniform strain at different intercritical annealing temperatures $\left(770^{\circ} \mathrm{C}, 790^{\circ} \mathrm{C}\right.$ and $\left.810^{\circ} \mathrm{C}\right)$. Uniform strain increases with increasing the tempering temperature and has minima at different times due to dynamic strain aging.

These values suggest that the mechanism responsible for dynamic strain aging in dual phase steel is the locking of dislocations by carbon atoms in ferrite and that the formation of clusters and/or transition carbides and carbide precipitation in martensite do not interfere with the dynamic strain process[17].
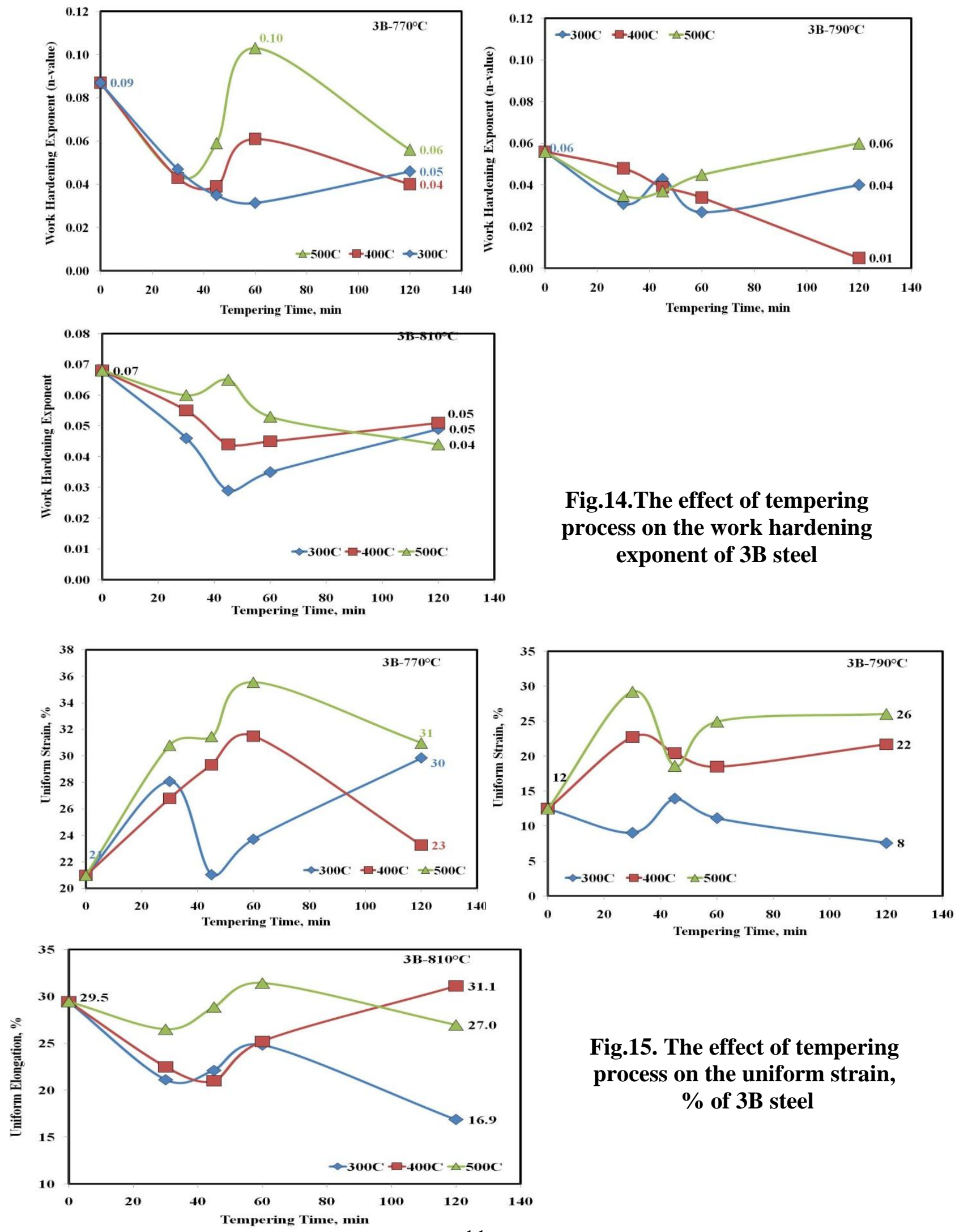

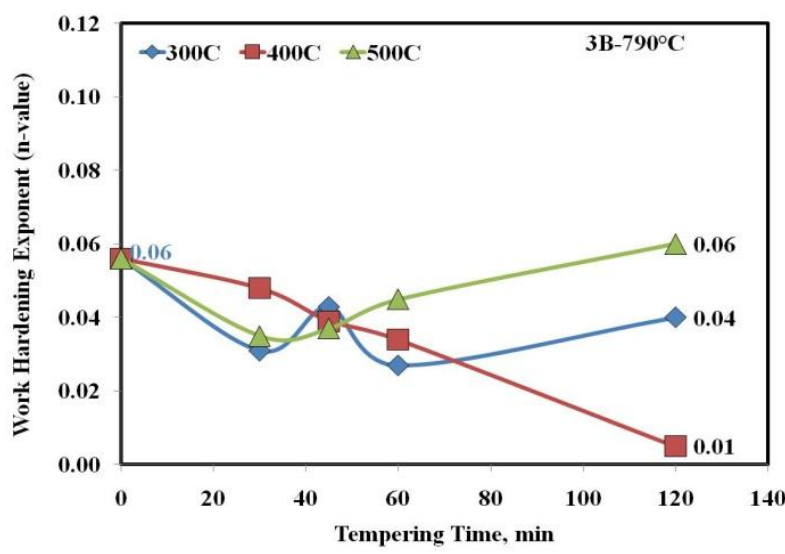

Fig.14.The effect of tempering process on the work hardening exponent of 3B steel
Fig.15. The effect of tempering process on the uniform strain, $\%$ of 3B steel 

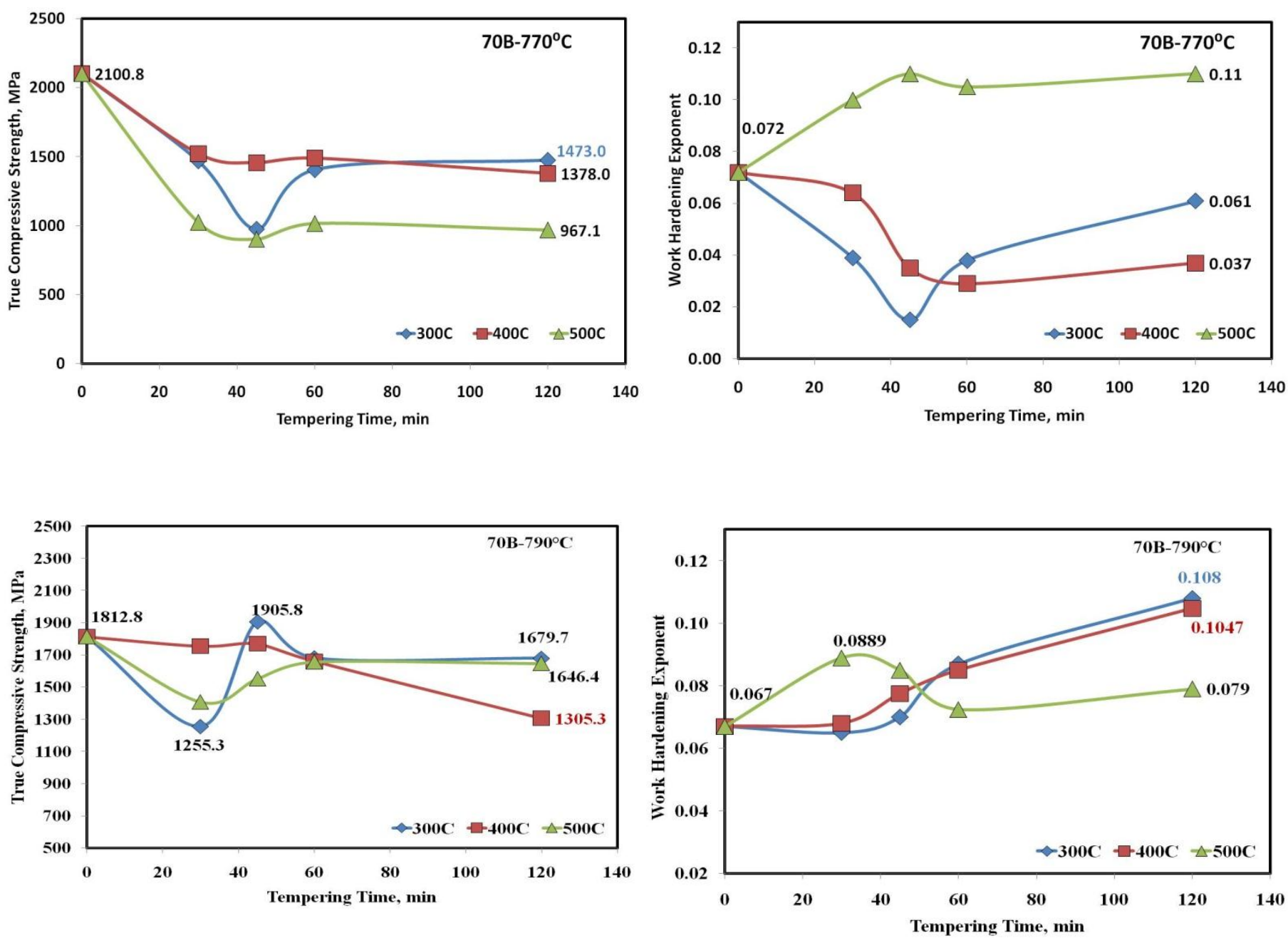

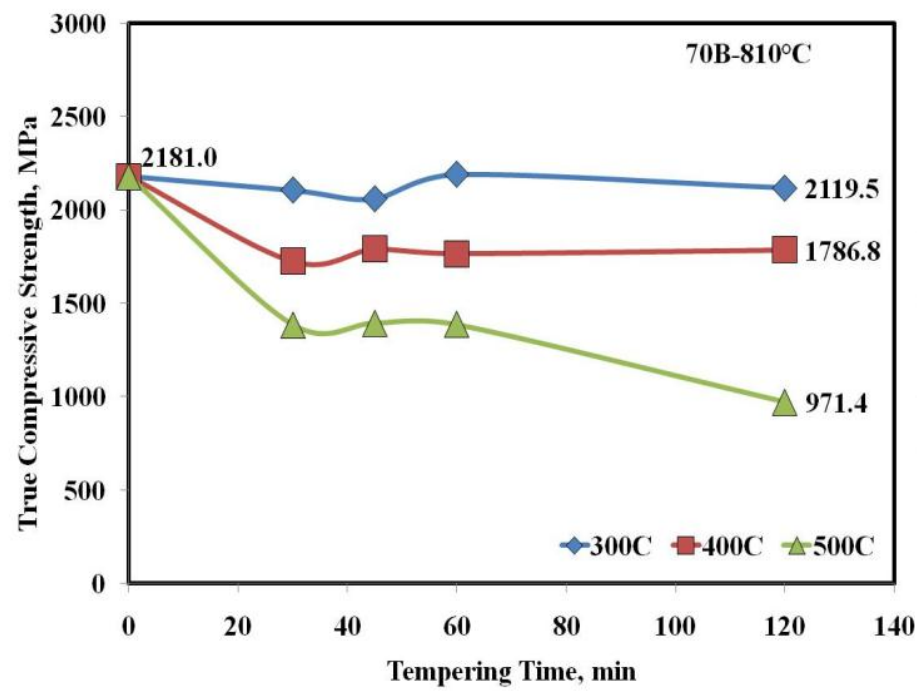

Fig.16. Effect of tempering

Process on the true compressive strength of 70B steel

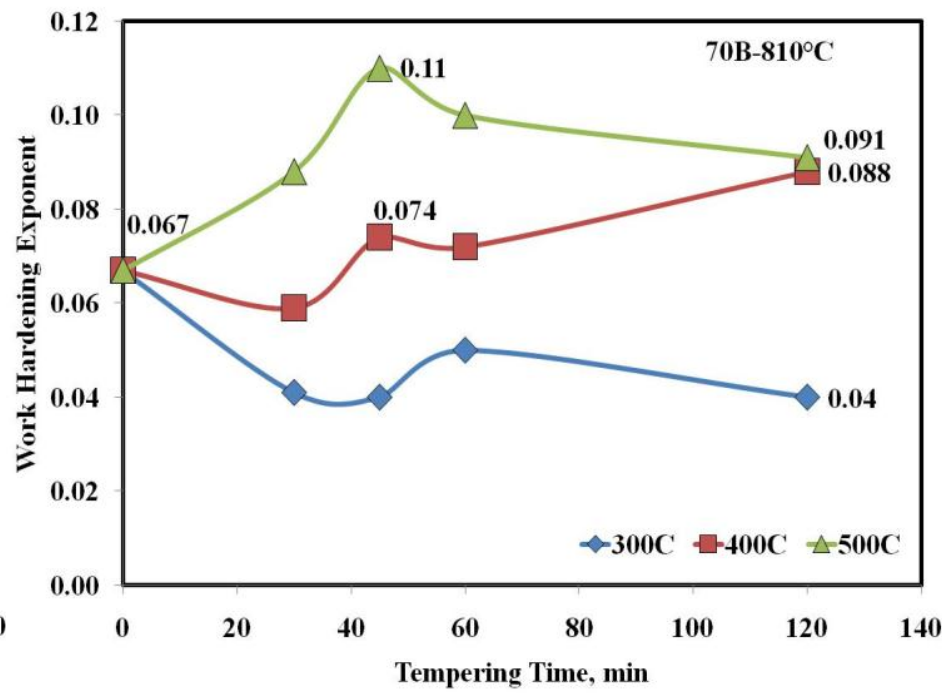

Fig.17. The Effect of tempering process on the work hardening exponent of 70B steel 

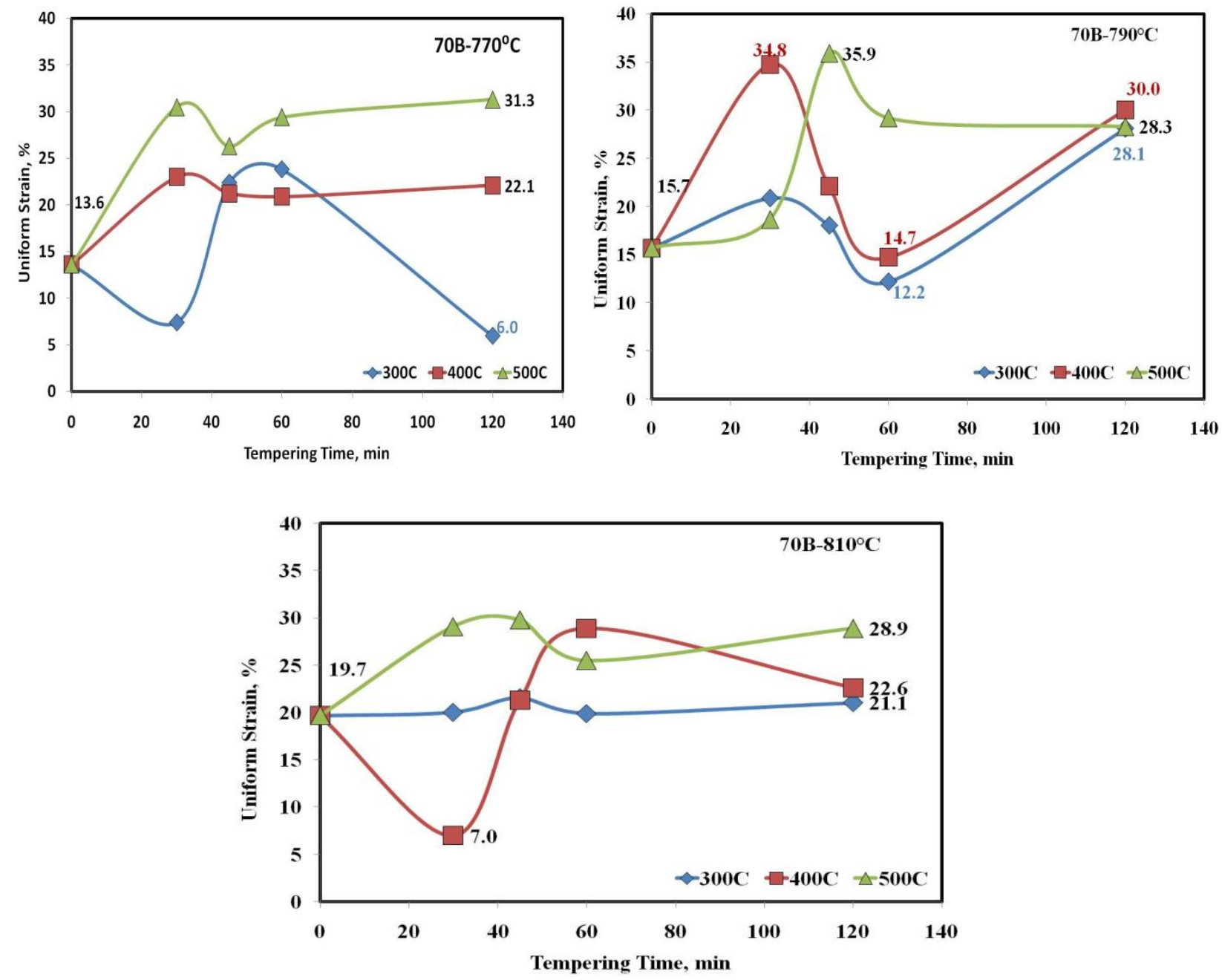

Fig.18.Effect of tempering process on the uniform strain, \% of $70 \mathrm{~B}$ steel

The phenomenological aspects of dynamic strain aging presented in this work, i.e., the presence of the PLC effect in the stress-strain curves; the maximum in the variation of flow stress, tensile stress and work hardening exponent with temperature; the minimum in the variation of uniform strain with temperature; as well as the shift of these maxima and minima to higher temperatures, indicate that the dual phase steels behave mostly in the same manner as steels of low carbon steels, alloyed or not, and perlitic steels, regarding dynamic strain aging[18].

\section{Conclusions}

The microstructure of as-cast and hot forged is ferrite-perlite and the grain size of hot forged steel is finer than that of as-cast steel. For both steels, increasing the inter-critical annealing temperature and boron content increase the martensite volume fraction and decreases the ferrite volume fraction subsequently the hardness value increases. For both steels increasing the tempering temperature and time cause the dissociation of martensite and decreases hardness value.

Increasing the inter-critical annealing temperature increases the true compressive strength due to increasing the martensite volume fraction while increasing the tempering temperature and time decreases the true compressive strength due to dissociation of martensite. Increasing the 
tempering temperature increases the compressive strain while increasing the tempering time sometimes increases and sometimes decreases it due to dynamic strain aging.

The dual phase steel studied in this work presented all the manifestations commonly related to dynamic strain aging: the PLC effect, the maximum in the variation of tensile stress with temperature, and the minimum in the variation of uniform strain with temperature.

\section{References}

[1] Xuan Liang, Jun Li and YingHong Peng, Materials Letters 62 (2008) 327-329.

[2] R. Nadlene, H.Esah, S.Norliana and M.A. Mohd Irwan, World Academy of Science, Engineering and Technology 74-2011.

[3] P.E. Repas, "Dual Phase and Cold-Forming Vanadium Steels in the Automobile Industry", Vanitec, Berlin, 1978.

[4] R.G. Davies, C.L. Magee, in: T. Davenport (Ed.), Structure and Properties of Dual Phase Steels, A.I.M.E., New York, 1979.

[5] A. Anazadeh Sayed and Sh. Kheirandish, Material Science and Engineering A 532 (2012) 21-25.

[6] A.K. Panda, D.S.Sama, R.I. Ganguly and S.Misra, Steel Res. Int.64 (51) (1993) 3-516.

[7] G.T.Eldis, The Influence microstructure and testing procedure on the measured mechanical properties of heat treated dual-Phase Steel, TMS-AIME, 1982,pp.310-316.

[8] Qingge Meng, Jun Li, Jian Wang, Zuogui Zhang and Lixiang Zhang, Materials and Design 30(2009) 2379-2385

[9] Sun S, Pugh M. Properties of thermomechanically processed dual-phase steels containing fibrous martensite. Mater Sci Eng A 2002; 335:298-308.

[10] Demir B, Erdog an M. The hardenability of austenite with different alloy content and dispersion in dual-phase steels. J Mater Process Technol 2008;208:75-84

[11] Geib MD, Matlock DK, Krauss G. The effect of intercritical temperature on the structure of niobium microalloying dual-phase steel. Metall Trans A 1980;11:1683-9

[12] M.K.Koul and C.L. McVicker: Met. Prog.,1976,vol.11, p.2.

[13] N. Shikana, M. Kurihard, and H. Tagaw: Thermec-88, I. Tamura, ed., Iron and Steel Institute of Japan, Tokyo, 1988, pp.98-105.

[14] X.p. Shen and R. Priestner, Metallurigical Transactions, vol 21A, September 19902547.

[15] http://en.wikipedia.org/wiki/Main_Page

[16] Mohammad Djahazi (Influence of boron distribution on precipitation and recrystallization in hot worked austenite), M.SC Thesis, Department of Mining and Metallurgical Engineering, McGill University, Montreal, Canada, p.5, Augest 1989.

[17] R.R.U. Queiroz, F.G.G. Cunha and B.M. Gonzalez "Study of dynamic strain aging in dual-phase steel", Materials Science and Engineering A 543(2012) 84-87

[18] W.R. Calado, C.S.B. Castro, O.J. Santos, R. Barbosa, B.M. Gonzalez, J. Mater. Sci. 43 (2008) 6005-6011. 